The excess of water above what would correspond to zinc oxide is evidently due to incomplete drying, as the substance cannot be heated to $100^{\circ}$ without decomposition.

I would take this opportunity of expressing my cordial thanks to Professor Crum Brown and Dr. Leonard Dobbin for many important suggestions received during the investigation.

CHEMICAL LABORATORY,

UNIVERSITY OF EDINBURGH.

\title{
VARIATIONS IN THE COMPOSITION OF RED LEAD.'
}

By DURAND WOODMan.

I $\mathrm{N}$ the manufacture of red lead and orange mineral, the color is ordinarily the property of first importance, since its chief use is as a pigment; and except so far as the color is dependent on the degree of oxidation, the latter is not the subject of special consideration.

For certain purposes, however, the degree of oxidation is important, and having occasion to examine a large number of samples of red lead from various sources, I adopted the method of digesting in saturated solution of normal lead acetate, by which the litharge in excess of that in combination as $\mathrm{Pb}_{3} \mathrm{O}_{4}$ (or $2 \mathrm{PbO} . \mathrm{PbO}_{2}$ ) is dissolved out and separated. The samples were all examined qualitatively for anything which might be considered as adulteration, but otherwise neglecting the small amounts of silica, lime, oxide of iron, and carbon dioxide normal to the commercial article, for the preliminary and approximate tests. In this way a series of results was obtained showing a variation in the amount of actual red lead from 41 to 92 per cent., as given in the tabular statement.

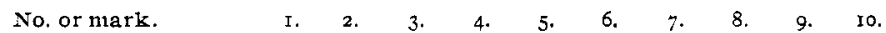
Red lead, $\mathrm{Pb}_{3} \mathrm{O}_{4} \ldots 5$ I $\ldots$.0 56.072 .075 .0 41.0 90.0 89.5 70.0 87.0 89.5 Litharge, $\mathrm{PbO} \ldots \ldots 49.044 .028 .025 .059 .0$ 10.0 10.5 30.0 I3.0 10.5

No. or mark. $\quad 517$. I40. C. BWI, C. BWL, C. I. B. BWL. I. B. Red lead, $\mathrm{Pb}_{4} \mathrm{O}_{4} \ldots$ 60.0 84.0 50.0 60.0 58.0 77.0 66.0 90.0 73.5 87.5 92.0 Litharge, $\mathrm{PbO} \ldots \ldots 40.0$ I6.0 50.0 40.0 42.0 23.0 34.0 I0.0 26.6 I2.5 8.0

The figures for red oxide are in most instances a little high because of the insoluble impurities which have not been determined and deducted, but the point which it is desired to bring out, is the large amount of monoxide in some samples,

1Read before the January meeting of the New York Section of the American Chemical Society, 
which has escaped oxidation; is separable by the lead acetate treatment; and which I believe, from the ease with which it is so separated, has no part in the chemical constitution of red lead. It seems to be simply an admixture and a measure of the incompleteness and imperfection of the roasting or oxidizing process.

In this connection some interesting data are given in Gmelin's Handbook, Vol. v, p. II8, concerning the degree of oxidation corresponding to the length of time on the hearth of the reverberatory furnace in the roasting process.

"Red lead" prepared from massicot with

I firing of 24 hours, contains 50.0 per cent. red lead $\left(\mathrm{Pb}_{8} \mathrm{O}_{4}\right)$.

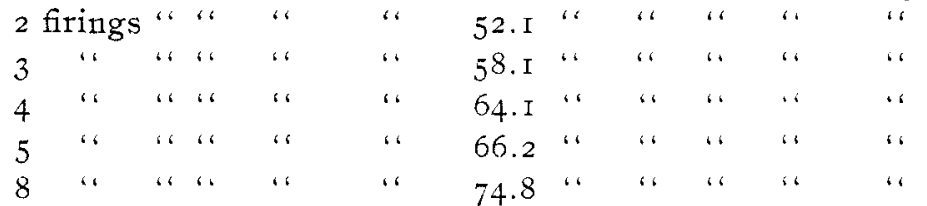

Red lead from "white lead" with 3 firings of 24 hours contained 95.3 per cent. red lead $\left(\mathrm{Pb}_{3} \mathrm{O}_{4}\right)$.

The analyses which I have made seem to show that little or no improvement has been made in the methods of manufacture from the standpoint of more complete oxidation.

The lead acetate treatment has a special interest in that it is one of the methods used by Dumas to demonstrate the individwality of the red oxide as a true chemical compound, although his results led him to the supposition that it was a sesquioxide $\left[\mathrm{Pb}_{2} \mathrm{O}_{3}\right]$ rather than a chemical union of the monoxide and peroxide.

The separation of the lead monoxide and red lead by this method is quite sharp, prolonged digestion in the acetate solution failing to produce any appreciable change in the weight of red lead.

By the usual methods of analysis, depending on the decomposition of the red lead into peroxide, which remains insoluble, and monoxide, which dissolves, no distinction is made between the monoxide in combination according to the formula $2 \mathrm{PbO}$. $\mathrm{PbO}_{2}$, and that which is present in excess and so easily removed by the acetate solution. An analysis of red lead is generally stated as follows : 


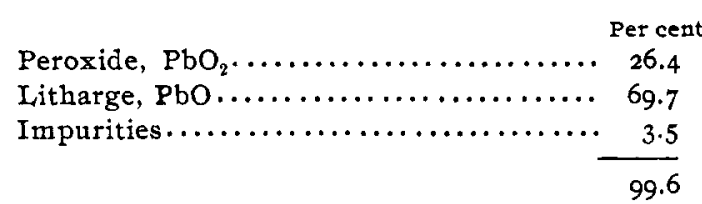

Since the formula $\mathrm{Pb}_{3} \mathrm{O}_{4}$ is accepted, and this compound is the essential part of a red lead, no matter what may be the views held as to whether the excess of $\mathrm{PbO}$ is a mere admixture, or in weak chemical combination; it would seem more satisfactory for commercial work to state an analysis as follows :

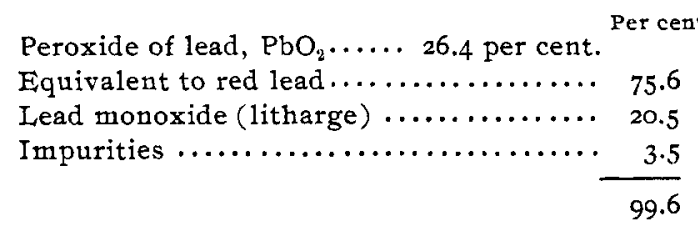

If the acetate method is used, we obtain the red lead figure directly ; if methods yielding the peroxide or its equivalent, the amount of peroxide found should be multiplied by the factor 2.866 to give the corresponding quantity of red lead.

\title{
DISCUSSION.
}

In regard to the lead monoxide removable by digestion of red lead in solution of lead acetate, Professor Sabin said that in making a cement of litharge and glycerine, considerable inert material, as sand or powdered glass, might be mixed with it without affecting the setting qualities; while on the contrary, red leads would not make a cement when mixed with glycerine. This would seem to indicate that the litharge is not in the same condition as if in simple admixture.

\section{SODIUM PEROXIDE AS A THIRD GROUP REAGENT.}

\author{
BY S. W. PARR.
}

Received February I, 1897 .

\begin{abstract}
GODIUM peroxide as a reagent has properties of a very $S$ unusual and striking character. These properties are no less valuable than peculiar, and indicate for this substance a prominent place in analytical work. The immediate object of this paper is to note the advantages and adaptability of sodium peroxide to qualitative analysis. By this means its numerous characteristics can be best illustrated. The specific data indi-
\end{abstract}

